\title{
Efficacy of Oxcarbazepine for Sleep-Related Leg Cramps: A Retrospective Study
}

\author{
Seon-Jae Ahn ${ }^{1,2}$, Yong-Won Shin ${ }^{1,3}$, Ki-Young Jung ${ }^{2}$ \\ ${ }^{1}$ Center for Hospital Medicine, Seoul National University Hospital, Seoul, \\ ${ }^{2}$ Department of Neurology, Seoul National University Hospital, Neuroscience Research Institute, \\ Seoul National University College of Medicine, Seoul, \\ ${ }^{3}$ Department of Neurosurgery, Seoul National University Hospital, Seoul, Korea
}

Received August 20, 2021

Revised October 12, 2021

Accepted October 28, 2021

Address for correspondence

Ki-Young Jung, MD, PhD

Department of Neurology,

Seoul National University Hospital,

Neuroscience Research Institute,

Seoul National University

College of Medicine,

101 Daehak-ro, Jongno-gu,

Seoul 03080, Korea

Tel: $+82-2-2072-4988$

Fax: +82-2-2072-2474

E-mail: jungky@snu.ac.kr
Objectives: Sleep-related leg cramps (SRLC) are common among older people. Severe clinical symptoms of SRLC usually cause great discomfort to patients. To date, many treatment drugs have been tried; however, there are currently no drugs approved for treating this condition. We aimed to assess the efficacy of a new drug, oxcarbazepine (OXC), in the treatment of SRLC. Methods: We retrospectively analyzed clinical outcomes following OXC administration. A daily dose of $150 \mathrm{mg}$ OXC was prescribed to control nocturnal leg cramps. Clinical outcomes were measured using the Clinical Global Impression Scale to confirm the effectiveness of OXC. Results: A total of $88.9 \%$ (16/18) of patients clinically improved four weeks after OXC prescription, and $94 \%$ (15/16) of patients continued to improve at the last follow-up (3-6 months). None of the patients complained of side effects related to $150 \mathrm{mg}$ OXC. Conclusions: OXC may be a new medical option for treatment of SRLC.

J Sleep Med 2021;18(3):162-166

Keywords: Sleep; Muscle cramp; Oxcarbazepine.

\section{INTRODUCTION}

Sleep-related leg cramps (SRLC) are painful sensations caused by sudden and intense involuntary contractions of muscles or muscle groups during which there is muscle spasm for several seconds. ${ }^{1}$ According to a previous survey study, frequent SRLC causes severe distress at bedtime, and the prevalence of SRLC increases with age. ${ }^{2,3}$ Therefore, many elderly people suffer from leg cramps at night. Although several predisposing factors, such as neuropathy, electrolyte imbalance, and endocrine or metabolic disorders, can affect these conditions, most cases are idiopathic.

Several medical treatments have been attempted for SRLC. Quinine has been known as the treatment of choice for decades. ${ }^{4}$ However, despite its strong effect on muscle cramps, the US Food and Drug Administration (FDA) banned quinine-containing drugs from the market because of severe toxicity, including fatal arrhythmia and thrombocytopenia. Many

This is an Open Access article distributed under the terms of the Creative Commons Attribution Non-Commercial License (https://creativecommons.org/licenses/by-nc/4.0) which permits unrestricted non-commercial use, distribution, and reproduction in any medium, provided the original work is properly cited. other medications, including magnesium oxide $(\mathrm{MgO}){ }^{5}$ vitamin B complex, ${ }^{6}$ naftidrofuryl, ${ }^{7}$ and calcium channel blockers, ${ }^{8}$ have also been evaluated for their therapeutic effects. Nevertheless, there is no available pharmacological drug of choice for the treatment of SRLC.

Oxcarbazepine (OXC), a 10-keto analog of carbamazepine, is used to treat epilepsy. Similar to carbamazepine, OXC can be used to treat focal or generalized seizures, and it can also be used to manage muscle cramps. ${ }^{9}$ Although a few case reports have shown the efficacy of this drug for muscle cramps in neuropathic conditions, no clinical trials have been conducted with OXC for the treatment of muscle cramps.

Considering that there is no effective medical treatment for SRLC, novel therapeutic options for this disease are required. We have experience in the use of low-dose OXC to control SRLC, and in this study, we retrospectively reviewed its clinical efficacy.

\section{METHODS}

All patients who visited the sleep clinic at the Seoul National 
University Hospital (Seoul, Korea) between January 2015 and December 2020 and who were clinically diagnosed with SRLC were reviewed. SRLC was diagnosed based on the diagnostic criteria of the International Classification of Sleep Disorders (ICSD)-3. ${ }^{1}$ The inclusion criteria were as follows: 1) clinical diagnosis of SRLC and 2) prescription of OXC for more than 4 weeks. The exclusion criterion was the unavailability of clinical data due to loss to follow-up.

The clinical severity of SRLC symptoms was evaluated using the Clinical Global Impression Scale-Severity (CGI-S). ${ }^{10}$ After 4 weeks of OXC use, the clinical effectiveness and response of symptoms were evaluated using the Clinical Global Impression Scale-Improvement (CGI-I). ${ }^{10,11}$ The CGI-S scores were as follows: 1 , normal; 2 , borderline mentally ill; 3 , mildly ill; 4, moderately ill; 5 , markedly ill; 6 , severely ill; and 7 , extremely ill. The CGI-I scores were as follows: 1 , very much improved; 2, much improved; 3 , minimally improved; 4 , no change; 5 , minimally worse; 6 , much worse; and 7 , very much worse. The CGI-S and CGI-I scores were evaluated by a single sleep disorder physician. CGI-I scores of 1-3 were classified as the clinical response group, while CGI-I scores of 4-7 were classified as the clinical nonresponse group.

Clinical data regarding previous medical history, comorbid sleep disorder, concurrent medication, and results of the nerve conduction study were also retrospectively analyzed.

The IRB of Seoul National University Hospital approved the study (IRB No. 2012-068-1180). The IRB approved a request to waive the documentation of informed consent.

\section{RESULTS}

A total of 44 patients were diagnosed with SRLC at the sleep clinic of Seoul National University Hospital, and 28 of these patients were prescribed OXC. Among them, seven patients were excluded due to loss to follow-up. One patient was excluded because of a short follow-up time (less than 4 weeks). Consequently, we retrospectively reviewed the records of the remaining 20 patients with SRLC treated with OXC.

The median age of the patients was 72 years (range, 41-81 years). Female patients were predominant (90\%). Among the 20 patients, seven (35\%) had restless leg syndrome (RLS). Obstructive sleep apnea (OSA) was observed in three patients (15\%) (Table 1). One patient (\#17) had both RLS and OSA. Six patients $(30 \%)$ were concurrently taking a dopamine agonist (ropinirole or pramipexole). Pregabalin was prescribed to six patients (30\%). Electrophysiological studies were conducted in 12 patients. Four patients (33\%) showed abnormal results in these electrophysiological tests, including three with lumbosacral radiculopathy and one with peripheral neuropathy (Table 2).
Table 1. Demographics of sleep-related leg cramps patients

\begin{tabular}{|c|c|}
\hline Characteristics & Value $(n=20)$ \\
\hline Age, median [range] & $72[41-81]$ \\
\hline \multicolumn{2}{|l|}{ Sex } \\
\hline Male & $2(10)$ \\
\hline Female & $18(90)$ \\
\hline \multicolumn{2}{|l|}{ Prev. medical Hx } \\
\hline HTN & $5(25)$ \\
\hline DM & $3(15)$ \\
\hline Angina & $1(5)$ \\
\hline HL & $2(10)$ \\
\hline Others (CML) & $1(5)$ \\
\hline None & $13(65)$ \\
\hline With RLS & $7(35)$ \\
\hline With OSA & $3(15)$ \\
\hline \multicolumn{2}{|l|}{ NCS results $(n=12)$} \\
\hline Normal & $8(67)$ \\
\hline L-S radiculopathy & $3(8)$ \\
\hline Neuropathy & $1(5)$ \\
\hline \multicolumn{2}{|l|}{ Baseline CGI-S } \\
\hline $4-5$ & $19(95)$ \\
\hline $1-3$ & $1(5)$ \\
\hline \multicolumn{2}{|l|}{ CGI-I (4 w) } \\
\hline $4-5$ & $2(10)$ \\
\hline $1-3$ & $16(80)$ \\
\hline Not checked & $2(10)$ \\
\hline \multicolumn{2}{|l|}{ CGI-I (last f/u) } \\
\hline $4-5$ & $1(5)$ \\
\hline $1-3$ & $15(75)$ \\
\hline Not checked & $4(20)$ \\
\hline \multicolumn{2}{|l|}{ OXC dose } \\
\hline $150 \mathrm{mg}$ & $19(95)$ \\
\hline $300 \mathrm{mg}$ & $1(5)$ \\
\hline
\end{tabular}

Data are presented as n (\%) unless otherwise indicated. CGI-I, Clinical Global Impression-Improvement; OXC, oxcarbazepine; NCS, nerve conduction study; DM, diabetes mellitus; HTN, hypertension; CML, chronic myelogenous leukemia; HL, hyperlipidemia; L-S, lumbosacral

The severity of nocturnal cramps was evaluated using CGI scores. The median CGI-S score was 4 (range, 3-5). Most patients (95\%) complained of moderate to severe symptoms (CGI-S, 4-5) of SRLC. After taking OXC for 4 weeks, 88.9\% $(16 / 18)$ of the patients showed clinical improvement (CGI-I, 1-3) (Fig. 1). Two patients showed no clinical improvement. The CGI-I assessed at the last follow-up visit (3-6 months) showed lasting clinical effects of OXC with 94\% (15/16) of the patients continuing to show clinical efficacy with $\mathrm{OXC}$, while 


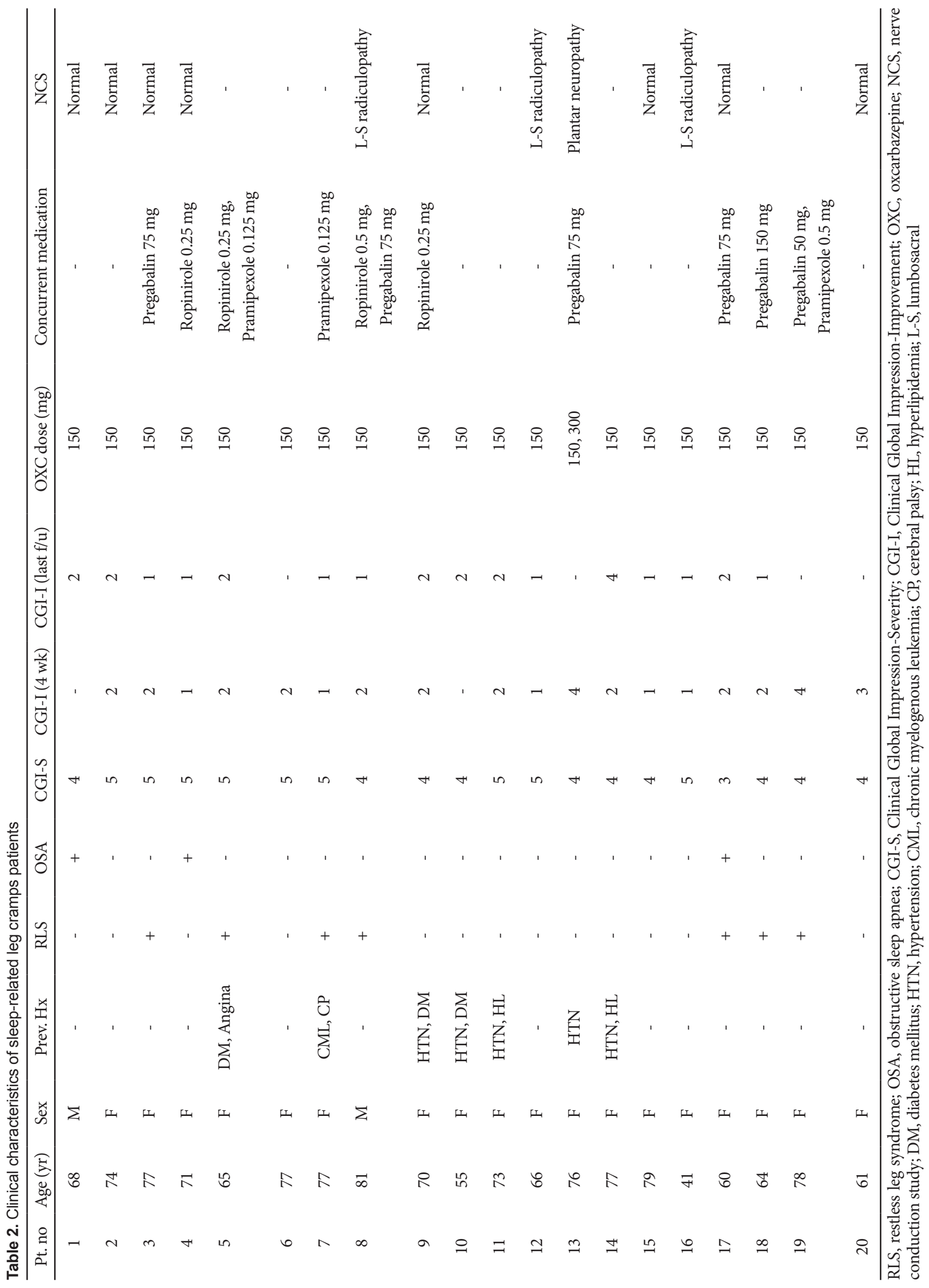




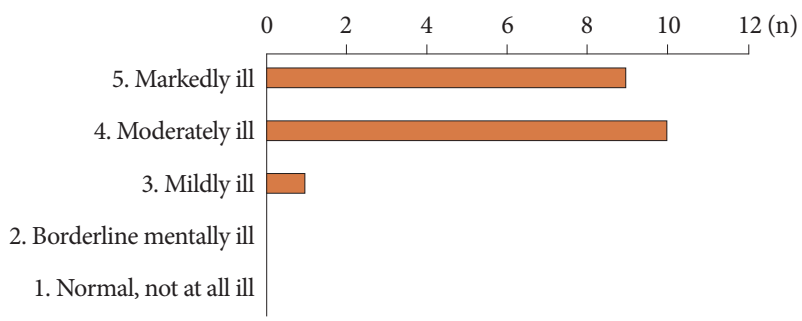

A

CGI-S (baseline)

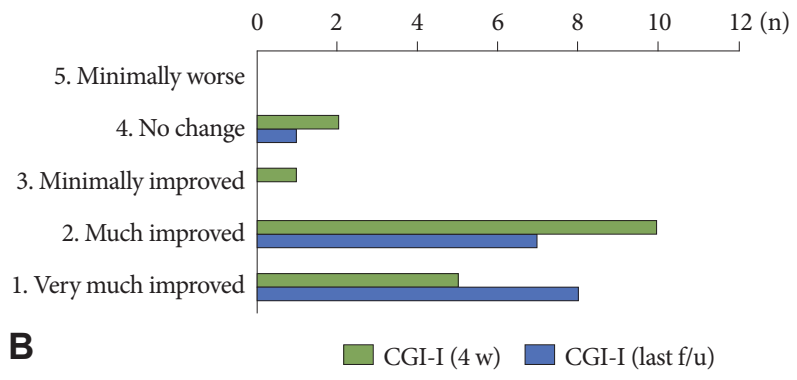

B

Figure 1. Clinical Global Impression Scale scores based on sleep-related leg cramps (SRLC). A: Orange bars show that most SRLC patients $(95 \%)$ before treatment had moderate to severe symptoms of muscle cramps. B: Green bars show that $88.9 \%$ of patients (16/18) clinically improved after taking oxcarbazepine for 4 weeks. Blue bars show that clinical efficacy was maintained until the last follow-up period (3-6 months) in 94\% of the treated patient (15/16). CGI-S, Clinical Global Impression Scale-Severity; CGI-I, Clinical Global Impression Scale-Improvement.

only one patient had no clinical response (Fig. 1).

The prescribed initial dose of OXC was $150 \mathrm{mg}$ once daily at bedtime. Combining the results from 4 weeks and the last follow-up visit, clinical effectiveness was obtained in 95\% $(19 / 20)$ of the patients at a dose of $150 \mathrm{mg}$. Only one patient was prescribed $300 \mathrm{mg}$ OXC because there was no clinical response at $150 \mathrm{mg}$. The clinical effectiveness of this increased dose of OXC could not be evaluated because the patient did not visit the clinic again. None of the patients showed adverse effects of OXC, such as hyponatremia, skin rash, leukopenia, or liver function test abnormalities.

\section{DISCUSSION}

In our retrospective study, OXC showed excellent efficacy in controlling SRLC. Most patients showed significant improvement with low-dose OXC. Our clinical series suggests three main points. First, OXC had significant effects on controlling muscle cramps at night. Second, a low dose of OXC (150 mg) was sufficient to induce a clinical response. Finally, there were no clinical adverse effects following low-dose OXC administration.

The pathogenesis of muscle cramps is high-frequency firing of motor neurons following muscle contraction. Rhythmic motor neuron firing can be generated by sodium conduction in the inner membrane during the after-polarization potential, during which the internal potassium conductivity is generally reduced. Sodium channel blockers may stabilize neuronal membrane equilibrium and can also contribute to preventing muscle contraction. ${ }^{12}$ It has been suggested that pharmacological therapeutic options for neurogenic muscle cramps and SRLC are not different. ${ }^{13}$ Therefore, we believe that theoretically OXC can be used as a drug to prevent muscle contraction and SRLC.

Quinine has been proven to be effective in several clinical trials and meta-analyses. ${ }^{14}$ However, it has been banned by the US FDA for use in treatment of leg cramps because of its severe adverse effects, such as thrombocytopenia, arrhythmia, visual impairment, and blindness.

Magnesium supplements are well known for their efficacy in treating abnormal muscle contractions. In 2017, a randomized clinical trial was conducted to assess $\mathrm{MgO}$ supplementation. ${ }^{5}$ A total of 94 patients were randomly assigned to $\mathrm{MgO}$ or placebo drug groups. In this study, $\mathrm{MgO}$ was effective in decreasing the frequency of nocturnal cramps. However, $\mathrm{MgO}$ failed to show clinical superiority compared to placebo.

A few studies have attempted to control muscle cramps with antiepileptic drugs (AEDs). Gabapentin has shown positive results in the context of diseases such as neuropathy, radiculopathy, multiple sclerosis, and Parkinson's disease. ${ }^{15}$ Levetiracetam was used to control muscle cramps in patients with amyotrophic lateral sclerosis. ${ }^{16}$ Carbamazepine, a structural analog of OXC, was used to treat cramp-fasciculation syndrome. ${ }^{17}$ In South Korea, a small retrospective study showed good efficacy with phenytoin in patients with SRLC. ${ }^{18}$ In this study, $81.3 \%$ of patients reported a significant reduction in SRLC frequency after taking 100-200 mg of phenytoin. Similar to phenytoin, we believe that OXC may be a therapeutic option for SRLC.

As an AED, OXC is usually administered twice daily at a dose of 600-1,200 mg/day. In this study, $150 \mathrm{mg}$ of OXC was administered once daily at bedtime. A low dose of OXC once daily was sufficiently effective to control muscle cramps. This may be due to the fact that unlike in controlling seizures, controlling muscle cramps does not require OXC to pass through the blood-brain barrier.

Our study has several limitations. First, our study was retrospective and not designed as a case-controlled study. We cannot exclude the effect of placebo in this study. Second, only a small number of patients were enrolled in the study. The fact that some patients were unable to confirm the CGI-I results due to loss to follow-up may have affected the final results. Subsequent studies should be conducted with a larger number of patients. Third, the efficacy of treatment was subjectively measured using the CGI scores. Objective findings of cramp fre- 
quency and severity need to be investigated in future studies.

In conclusion, our retrospective study showed that a daily dose of $150 \mathrm{mg}$ OXC was sufficient for controlling SRLC. Low doses of OXC were not only effective but also had few side effects. However, a randomized case-control study is warranted to validate the efficacy of OXC in SRLC.

\section{Conflicts of Interest}

The authors have no potential conflicts of interest to disclose.

\section{ORCID iDs}

Seon-Jae Ahn

Yong-Won Shin

Ki-Young Jung

https://orcid.org/0000-0003-0520-7812

https://orcid.org/0000-0002-6781-7782

https://orcid.org/0000-0001-5528-9081

\section{Author Contributions}

Conceptualization: Ki-Young Jung. Data curation: Seon-Jae Ahn, YongWon Shin. Formal analysis: Seon-Jae Ahn. Funding acquisition: Ki-Young Jung. Investigation: Ki-Young Jung. Methodology: Seon-Jae Ahn, KiYoung Jung. Project administration: Yong-Won Shin, Ki-Young Jung. Resources: all authors. Software: Yong-Won Shin. Supervision: Yong-Won Shin. Validation: Yong-Won Shin. Visualization: Seon-Jae Ahn. Writingoriginal draft: Seon-Jae Ahn. Writing_review \& editing: Seon-Jae Ahn, Ki-Young Jung.

\section{Funding Statement}

This work was supported by a National Research Foundation of Korea (NRF) grant funded by the Korean government (MSIP) (2017R1A2B2012280).

\section{REFERENCES}

1. American Academy of Sleep Medicine. The international classification of sleep disorders. 3rd ed. Darien: American Academy of Sleep Medicine, 2014.

2. Monderer RS, Wu WP, Thorpy MJ. Nocturnal leg cramps. Curr Neurol Neurosci Rep 2010;10:53-59. https://doi.org/10.1007/s11910-009-0079-5.

3. Grandner MA, Winkelman JW. Nocturnal leg cramps: prevalence and associations with demographics, sleep disturbance symptoms, medical conditions, and cardiometabolic risk factors. PLoS One 2017;12:e0178465. https://doi.org/10.1371/journal.pone.0178465.

4. Man-Son-Hing M, Wells G, Lau A. Quinine for nocturnal leg cramps: a meta-analysis including unpublished data. J Gen Intern Med 1998;13:600606. https://doi.org/10.1046/j.1525-1497.1998.00182.x.

5. Roguin Maor N, Alperin M, Shturman E, et al. Effect of magnesium ox- ide supplementation on nocturnal leg cramps: a randomized clinical trial. JAMA Intern Med 2017;177:617-623. https://doi.org/10.1001/jamainternmed.2016.9261.

6. Chan P, Huang TY, Chen YJ, Huang WP, Liu YC. Randomized, double-blind, placebo-controlled study of the safety and efficacy of vitamin B complex in the treatment of nocturnal leg cramps in elderly patients with hypertension. J Clin Pharmacol 1998;38:1151-1154. https:// doi.org/10.1177/009127009803801210.

7. Young JB, Connolly MJ. Naftidrofuryl treatment for rest cramp. Postgrad Med J 1993;69:624-626. https://doi.org/10.1136/pgmj.69.814.624.

8. Baltodano N, Gallo BV, Weidler DJ. Verapamil vs quinine in recumbent nocturnal leg cramps in the elderly. Arch Intern Med 1988;148:19691970. https://doi.org/10.1001/archinte.1988.00380090055015.

9. Katzberg HD, Khan AH, So YT. Assessment: symptomatic treatment for muscle cramps (an evidence-based review): report of the therapeutics and technology assessment subcommittee of the American academy of neurology. Neurology 2010;74:691-696. https://doi.org/10.1212/ WNL.0b013e3181d0ccca.

10. Busner J, Targum SD. The clinical global impressions scale: applying a research tool in clinical practice. Psychiatry (Edgmont) 2007;4:28-37.

11. Bogan RK, Fry JM, Schmidt MH, Carson SW, Ritchie SY. Ropinirole in the treatment of patients with restless legs syndrome: a US-based randomized, double-blind, placebo-controlled clinical trial. Mayo Clin Proc 2006;81:17-27. https://doi.org/10.4065/81.1.17.

12. Swash M, Czesnik D, de Carvalho M. Muscular cramp: causes and management. Eur J Neurol 2019;26:214-221. https://doi.org/10.1111/ ene.13799.

13. Katzberg HD. Neurogenic muscle cramps. J Neurol 2015;262:1814-1821. https://doi.org/10.1007/s00415-015-7659-x.

14. Man-Son-Hing M, Wells G. Meta-analysis of efficacy of quinine for treatment of nocturnal leg cramps in elderly people. BMJ 1995;310:1317. https://doi.org/10.1136/bmj.310.6971.13.

15. Serrao M, Rossi P, Cardinali P, Valente G, Parisi L, Pierelli F. Gabapentin treatment for muscle cramps: an open-label trial. Clin Neuropharmacol 2000;23:45-49. https://doi.org/10.1097/00002826-20000100000008.

16. Bedlack RS, Pastula DM, Hawes J, Heydt D. Open-label pilot trial of levetiracetam for cramps and spasticity in patients with motor neuron disease. Amyotroph Lateral Scler 2009;10:210-215. https://doi. org/10.1080/17482960802430773.

17. Tahmoush AJ, Alonso RJ, Tahmoush GP, Heiman-Patterson TD. Cramp-fasciculation syndrome: a treatable hyperexcitable peripheral nerve disorder. Neurology 1991;41:1021-1024. https://doi.org/10.1212/ wnl.41.7.1021.

18. Kim KM, Lee DH, Lee Y, et al. Efficacy of phenytoin for nocturnal muscle cramps: a preliminary study. J Korean Neurol Assoc 2014;32:254258. 